\title{
The Possibility of Space Tourism in India: Issues and Concerns
}

\author{
Mukesh Mohan Pandey \\ Lecturer, Department of Business Administration, St Theresa International College, 1 Moo 6, Rangsit-Nakhon \\ Nayok Road (Klong 14), Bungsan, Ongkarak, Nakhon Nayok-26120, Thailand
}

\begin{abstract}
Dennis Tito opened the eyes of world to the idea of orbital space tourism when he became the first private space traveler in 2001. Three years later, the Burt Rutan and Paul Allen led team of Mojave Aerospace Ventures won Ansari X-Prize by successfully completing two piloted sub-orbital flights of a reusable vehicle to 100 kilometers in altitude within a span of two weeks. This accomplishment demonstrated to the public and government managers the potential for entrepreneurial commercial activities to change the landscape of the space industry. And now we can see renowned organization like Virgin Galactic, Space X, Armadillo Aerospace, Blue Origin, Bigelow Aerospace and Xcor Aerospace has already not only joined the race of space tourism project but they are also making a remarkable progress. However we see Indian venture has not yet joined for space tourism project. Meanwhile it is believed that India can play a vital role in developing a very cost effective solution for space travel technologies, thus it imperative to investigate the possibility of space tourism in India.

In this paper the potential and possibility of space tourism industry in India has been explored. It examines the potential market and cost structure for both suborbital and orbital space travel. Apart from this major issues with the development of the fledgling space tourism industry in India has been identified which need to be addressed in order to promote the growth of this industry.
\end{abstract}

Keywords LEO: Low Earth Orbit, ISS: International Space Station, IRR: Internal Rate of Return, NPV: Net Present Value

Accepted Date: 21 Nov 2012

\section{Introduction}

Space tourism is the concept of tourists flying into the space primarily for sheer enjoyment (Accelteon Partners Inc., 2008). In other words space tourism can be defined as: "A vision of having affordable space transportation system for as many people as possible going to space as space tourists". A "space tourist" is a person who travels to and experiences space for adventure and recreation. In sum and substance space tourism connotes to the provision of facilities and services that enables humans to access and experience space for purposes of adventure and recreation. In the last decade a lot of productive work has been done in this area and now we have few space tourists who have paid multi-million dollars to be in the space. Thanks to the organizations like Space Adventures who has arranged this facility on Russian Soyuz vehicle. However we see the sub-orbital segment of space tourism is still in its infancy and appears to be futuristic. Keeping in view the current scenario regarding the development of space tourism we can foresee three kind of trip:

a) Orbital travel with stay at International Space Station (ISS)

b) Sub-orbital travel

c) Point-to-point

A) Orbital travel with stay at ISS: In this type of travel the passenger gets on board of spacecraft and goes in Low Earth Orbit (LEO) stays at ISS for one or two week. Following are the space tourists who have so far experienced this travel. Tourists have been launched only on Soyuz vehicle.

\begin{tabular}{|l|l|l|l|l|}
\hline Year & Space Tourist & Nationality & $\begin{array}{l}\text { Duration of Flight \& } \\
\text { Vehicle }\end{array}$ & Amount Paid in USD \\
\hline 2001 & Denis Tito & American & 8 days (Soyuz) & 20 Million \\
\hline 2002 & Mark Shuttleworth & South African & 11 days (Soyuz) & 20 Million \\
\hline 2005 & Gregory Oslen & American & 11 days (Soyuz) & 20 Million \\
\hline 2006 & Anousheh Ansari & American/ Iranian & 12 days (Soyuz) & 20 Million \\
\hline 2007 & Charles Simyoni & Hungarian/ American & 15 days (Soyuz) & 25 Million \\
\hline 2009 & Guy Laliberte & Canadian & 11 days (Soyuz) & 35 Million \\
\hline 2009 & Charles Simyoni & Hungarian/ American & 15 days (Soyuz) & 35 Million \\
\hline
\end{tabular}

Table 1: List of tourist participated in Orbital flight 
B) Sub-orbital travel: In sub-orbital travel the spaceships would take passengers up to space at an altitude of about 62 miles (100 kilometers) -- commonly known as the edge of space -- before returning to Earth. These passengers would get a glimpse of the edge of our planet and the blackness of space while experiencing several minutes of weightlessness (Chow Dennis, 2011).

C) Point-to-point inter-continental sub-orbital travel: Sub-orbital travel is capable of flights from one part of the world to another in relatively shorter period of time than jet engine powered aircraft. For instance, Virgin Galactic has mentioned that its' first sub-orbital vehicle could also be used to make super-fast intercity trips (New Scientist, 2006). If the cost of sub-orbital flights drops significantly, intercity flight may have potential applications for high urgency cargo flights, urgent military responses, or even business or commercial travel where passengers experience the excitement of space while travelling from continent to continent. Thus this trip is going to bring a remarkable change in human life.

\section{Space tourism: present scenario}

Today, space tourism is very much in its infancy, with a strong sense of optimism and enthusiasm amongst the pioneers developing the industry. Perhaps the greatest motivation behind the development of the industry is the lure of a potentially large, untapped market. A foundation study performed by Futron Corporation indicated that the market for sub-orbital travel alone could be between 10,000 and 20,000 passengers, bringing in almost $\$ 700$ million in revenue annually, by 2021( Futron, 2006). Entrepreneurs are hungry to seize unrealized profits, and a new space race, sometimes referred to as the "Private Space Race", because it takes place primarily amongst private sector organizations and initiatives, has commenced. More highly publicized efforts to bravely pursue the space tourism industry include undertakings by well known entrepreneurs such as Sir Richard Branson (best known for his Virgin brand), Jeff Bezos (CEO, Amazon), and Elon Musk (Cofounder, PayPal). These entrepreneurs have decided to take the risk of pursuing the space tourism industry, in hopes of realizing potentially large returns. Altogether, however, more than 40 organizations worldwide are attempting to develop the space tourism market, including efforts in the United States, Russia, Canada, Argentina, Australia, China, India, Europe, and Israel (Pelton J.N., 2007). The majority of these organizations are in the business of developing vehicles for space travel, with the intent of operating the vehicles for space tourism. However, there are commercial firms who intend to provide other space tourism products and services, such as space hotels (e.g. Bigelow Aerospace), or creating and developing various space tour experiences (e.g. Space Adventures). Space Adventures is considered to be most successful company to date. This company has brokered for flight of all orbital space tourist mentioned in table 1 to ISS (Ashworth Stephen, 2005). Thus we see that Orbital space tourism has been possible since 2001. Now we are waiting for right technology of a suborbital spacecraft which would provide low cost access to space to the tourists. The advent of this trip would eventually lead us to Suborbital point-to-point travel.

Collins in one of his study has analyzed the macro-economic situation. The middle class populations are growing rapidly worldwide, but unemployment is at a post-war high, due to slowness of growth of new industries. This shows that as the space tourism industry would be key to creating new jobs and opening up new of new sector for entrepreneurs.

Keeping in view the above-mentioned rationale the companies pioneering for this project today would seek the first mover advantage and may be tomorrow's market leader for this sector. In connection to this we find that developed countries like USA, Japan, Russia, United Kingdom, France, Germany are taking the lead. However we find India missing the space race by private players. India has the opportunity now to join this exclusive club of nations to contribute in the possibility of space tourism.

In the last twenty five years, India's space programmes have achieved several successful missions and accomplishments. Today, the country is self-reliant in space technology as recently demonstrated by the "Chandrayaan-1" programme - encompassing the successful development and testing of a launch vehicle from scratch at a cost less than the cost of developing a passenger jet aircraft. With this unprecedented strength in integrated technology, India is presently in the position to advance further and embark upon new missions. With its immense competitive advantages, particularly in the space sector, India needs to move from the old era of technology-demonstration to the modern era of commercialisation by exploring new strategies and technologies for human spaceflight programmes and low-cost access to space. Space tourism is one such area where India can play a niche role with its affordable yet reliable solutions.

\section{Possible market for space tourism in India}

Understanding of the potential markets and demand is the key to examining the possibility of operations for space tourism in India. As based on Futron's Study space tourism consists of broadly two type of travel:

a) Suborbital Travel 
b) Orbital Travel

Now let us see for demand for each segment of space travel in India.

\section{a. Sub-orbital travel}

As per the preliminary pilot survey conducted by Centre for Aviation Studies (CAS), UPES Dehradun in India (UPES, 2011) ; the demand for sub-orbital tourism exists as given in figure 1 given below. As per their survey and forecast if the price of suborbital flight is USD 200,000 there is no demand till 2013 however in the forecast it has been assumed that the ticket price for the suborbital travel if decreased to the price of USD 150,000 the demand for the suborbital travel spurts with possibility of almost 4000 passengers in 2013 and finally number of passenger for suborbital travel increases to 8500 suborbital passengers in 2020. Again it has been assumed that the ticket price for suborbital travel has been decreased to USD 100,000 in 2020 again we see steep surge in demand almost four fold increase to almost 33000 passengers in 2021 and finally it reaches to 50000 passengers by 2025 . However this survey can't be treated as realistic as this survey was just done for a preliminary study.

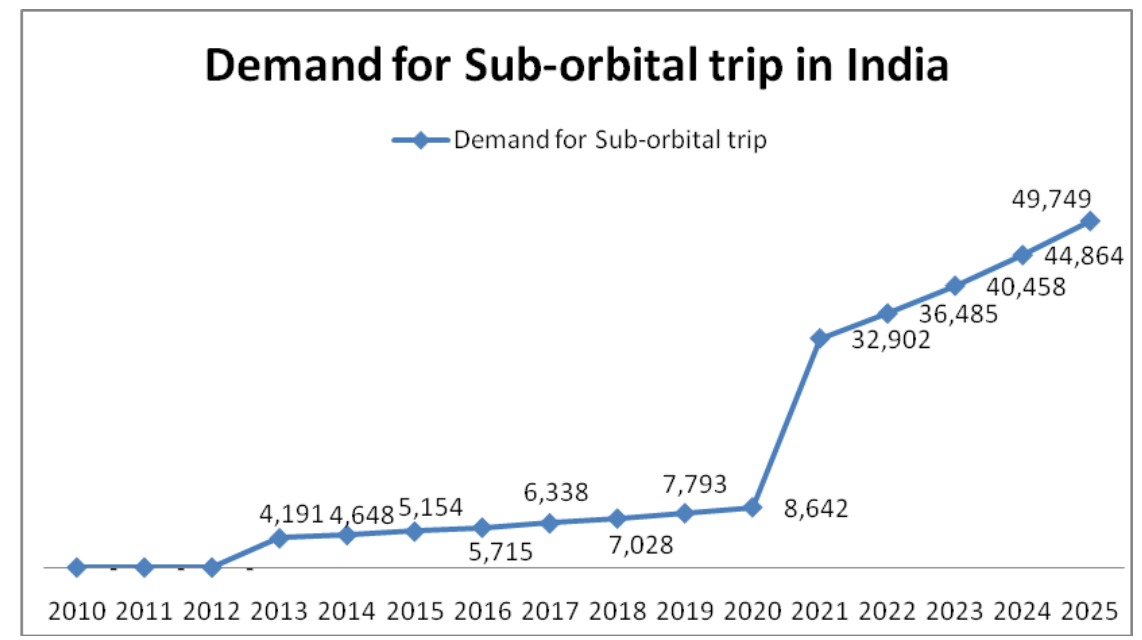

\section{Source: (UPES, 2011)}

Figure 1: Demand for Sub-orbital trip in India

The revenue projections for the suborbital travel market demonstrate the potential revenue that could be realized if all of the forecasted demand for flights could be met. Thus, in figure 2 given below it is observed that total revenues from suborbital trips start from almost USD 630 million in 2013 and increases to USD 5000 million in 2025. It should be noted that supply constraints on the market could significantly lower the potential number of passengers and therefore, revenue.

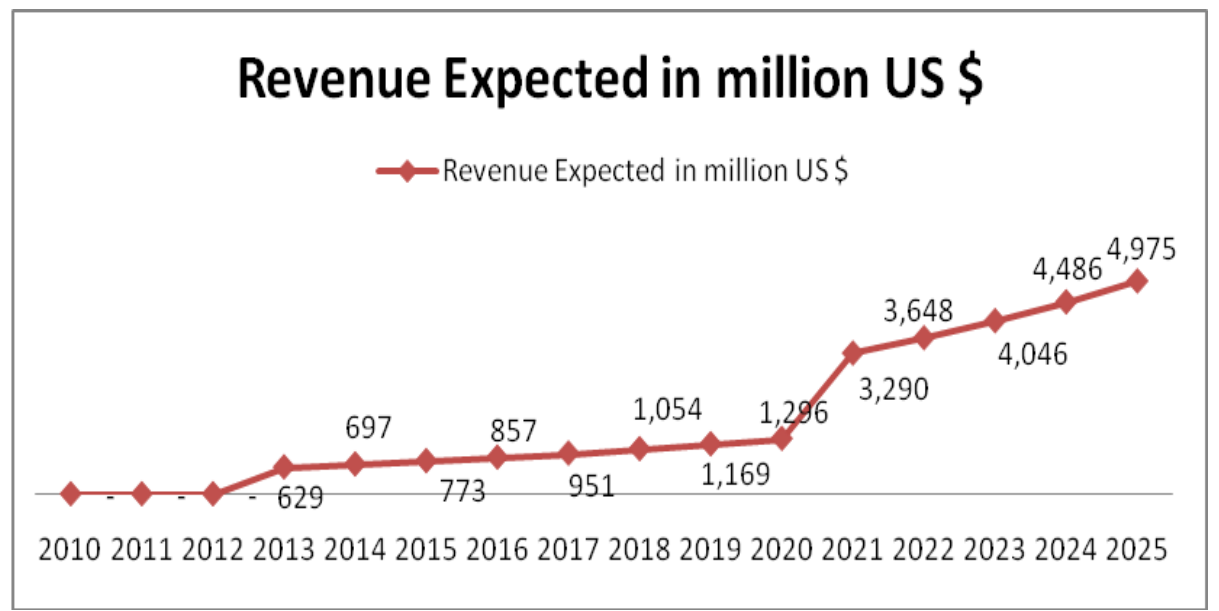

Source: (UPES, 2011)

Figure 2: Revenue expected from sub-orbital trip in India

\section{b. Orbital Travel}

As per the research study conducted by CAS for orbital travel it has been found that at the ticket price of USD 20 million there is possibility of two passengers that are willing to go for orbital travel from India 
(UPES, 2011). In this study following demand side constraints customers willingness to pay for orbital travel, net worth, participation after flip side description of travel, health status, unique experience. Apart from this one supply side constraint i.e. actual number of seats available for orbital travel per year is also place to reach suitable conclusion for demand. The supply side constraint becomes the main determinant to forecast the growth for orbital travel in India. Initially if all the seats are allocated to Indians customer there is possibility of two passengers each year from India. Meanwhile in this study it is assumed that by 2016 there will be extra flight of Soyuz per year. Therefore number of passengers going for orbital travel will increase to four. Therefore passengers carried for orbital travel from 2016 to 2020 is four. However, the current trend of carrying a two astronauts and single passenger on a Soyuz flight is subject to change with the introduction of a single astronaut and two passengers. It is assumed that this change will occur by 2020; therefore the Soyuz capsule would carry eight passengers per year in between 2020 to 2025 .

The forecast for orbital space travel results in a cumulative 8 passengers over the entire forecast period as the only means of providing the flight till now is through a Soyuz capsule.

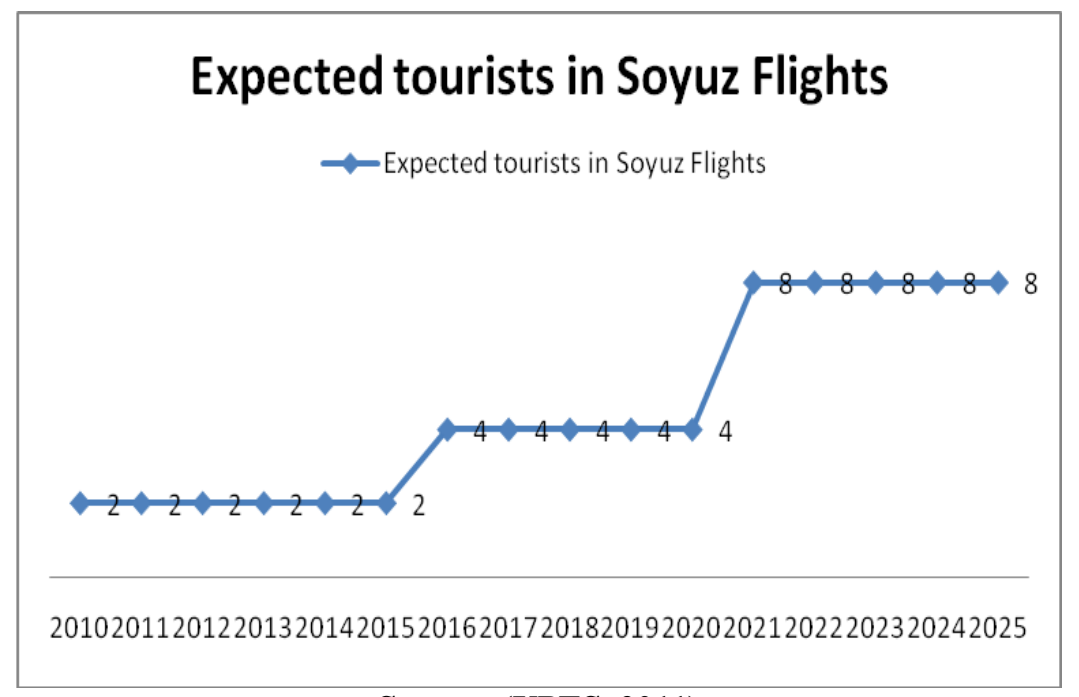

Source: (UPES, 2011)

Figure 3: Demand for Orbital trip in India

The revenue forecast for the orbital travel market demonstrates the potential revenue that can be realized if all of the demand for flights could be met. However supply remains a severe challenge as up until now, only the Soyuz rocket/capsule is capable of ferrying passengers into and out of orbit. Accordingly, it has been reasoned that till 2025 possibly no other agency would commence such type of travel. Thus, it has been found that at most supply projections can only fulfil demand for 8 passenger seats per year between 2020 and 2025 . This is shown in Figure 3 above. It has been also found that total revenue from orbital trips would start at USD 40 million in 2010 and it increase to USD 160 million in 2025. (See Figure 4 below). It should be noted that supply constraints on the market could significantly lower the potential number of passengers and, therefore the revenue picture could be more promising than as painted above.

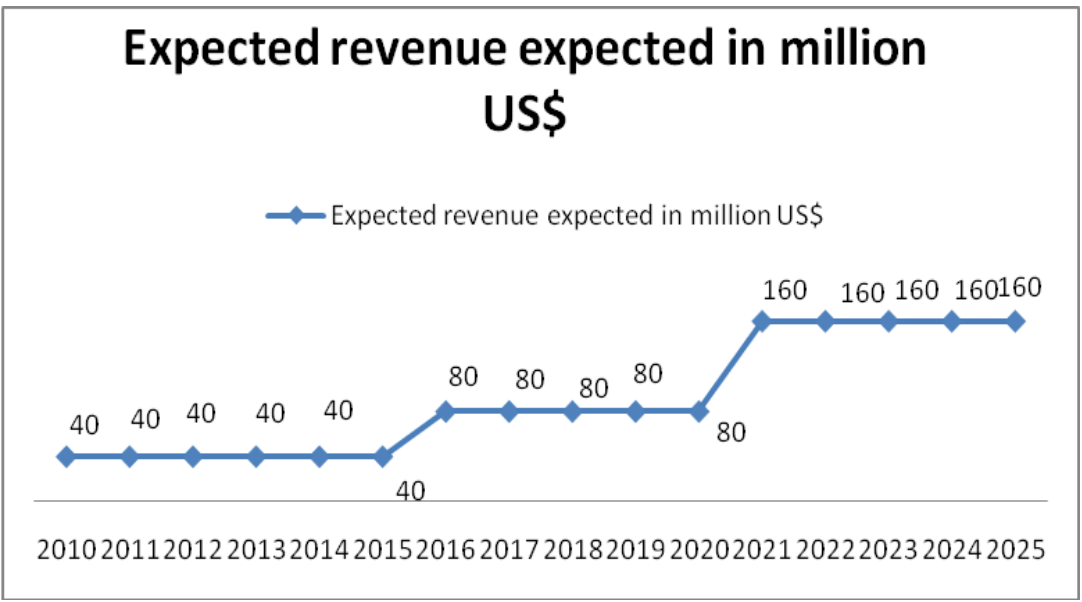

Source: (UPES, 2011)

Figure 4: Expected revenue from Orbital trip in India 


\section{Issues \& Concerns}

At this point of time, it is still too early to paint a comprehensive picture of the state of space tourism in India. In practice, any effort to put together a business plan for the conduct of space tourism in India will be faced with a variety of roadblocks. Given below are the major impediments, which need to be addressed for the start-up of space tourism in India.

\section{a. A strong legislation for Space Tourism}

For the purpose of initiating of space tourism in India, a law is required. The law would deal with several subjects' viz. compulsory registration of spacecraft, nationality, marking, fitness of spacecraft, air worthiness/space worthiness, medical standards, licensing of space crew and safety precaution for launching etc. Apart from it a strong legislation is required for participation of private bodies in space tourism. The private parties (other than Government bodies) can be entrusted with different activities in connection with space tourism. The role of the Government in the establishment of a new industry is to help its private sector to develop and encourage the growth of domestic economies. Though Government role includes legal responsibility for authorizing and supervising private space activities, the space industry has yet to grow commercially. Incidentally the Prices per ticket for trips in space would largely be dependent on efficiencies of private industry and continued progress with technology development.

\section{b. Availability of Appropriate Space Vehicles}

By definition, a vehicle that can be used in the conduct of space tourism is one that can safely transport passengers to an altitude higher than $100 \mathrm{~km}$ above the surface of the Earth. This is believed to the altitude at which space begins, meaning that the passengers can experience weightlessness. Currently, the global space tourism industry is at the preliminary stage of developing different kinds of vehicles capable of transporting human passengers into sub-orbit. There is not in existence a fully developed, confidently safe and dedicated spacecraft capable of being used to offer space travel to human passengers on a commercial basis. This factor alone creates a lot of uncertainty when one attempts to assess the viability of the space tourism sector.

\section{c. Public Interest}

To some extent, however, the lack of public interest in space activities can be described to the absence of awareness about commercial space activities in the context of leisure and travel/tourism. Lately, the great majority of Indians only think about 'space' in connection with 'cyberspace' since that is the perspective from which space activities are most visible: the use of space has the greatest impact on the present national security scenario and how the government is dealing with it. Nowadays, upwardly mobile, mostly unmarried professionals in the 25-35 age groups who may not as yet be HNIs but are nevertheless earning very high salaries are quite likely to experiment with new things such as space tourism.

Moreover, people's interest in space activities can be stimulated with the help of media. Things like reality shows in which the winner gets a free ticket for suborbital travel could further enhance the interest of the public in space. Besides those, things like awarding frequent flyer points redeemable for free space travel could also attract space tourists. Already, Virgin Galactic is offering such promotions.

\section{d. The Green Factor}

Space tourism operators need to document the carbon dioxide emissions resulting from their flights and supporting operations in a holistic way. The initial calculations show that a typical suborbital flight using technology similar to that of the Bristol Space-planes Ascender will produce three tonnes of carbon dioxide per flight per passenger. This is equivalent to a London to Singapore return flight in a conventional aircraft. Bristol Space-planes has also stated that its suborbital flights will produce emissions equivalent to a London to New York business class flight. It is interesting to look at the effects of scaling up the suborbital space tourism industry. A recent study published by Futron predicts that there will be up to 852 flights a year out of the New Mexico spaceport. If on a global basis, it has been assumed that there would be 3,000 flights a year with 6 passengers on each flight and 3 tonnes of emissions per passenger, the total emissions per annum will be 54,000 tonnes. By way of comparison, this is equivalent to the emissions produced from 5 days of continuous operation of a 500MW gas-fired power station, or from 3 days of electricity consumption if UK consumers leave their electrical items such as TVs on standby. In contrast, British Airways produced 16,132,000 tonnes of emissions in 2005 mainly from its flight operations.

A calculation of the carbon dioxide emissions from an orbital trip to the ISS on a Soyuz launcher suggests that the emissions are 143 tonnes per passenger. Clearly, any scaling up of orbital tourism will not use Soyuz technology. It is interesting to note that the global space tourism industry has already recognized the environmental impact of its operations and is taking steps to mitigate them. Virgin Galactic for instance has stated that its space-plane will use renewable energy and may even be a net energy producer, a feature which could make it "carbon negative". 


\section{e. Estimating the Cost of Suborbital Flights and Financial Planning}

As shown in Table 2 below, the design, development, testing, evaluation and production of five spaceships and two mother ships is estimated to cost around USD 350 million (Coppinger Rob, 2009) Virgin Galactic has signed a production agreement with Mojave Aerospace Ventures to use the Mojave spaceport for twenty years at a total cost of USD 27.5 million (Space Future Consulting, 2008). According to rules proposed in the U.S. a company offering suborbital travel services would incur costs of about USD 2,384,676 for 10 years, (Helm, Burt, 2004). Therefore in the span of twenty years it would incur costs of US $\$ 4,769,352$. The operating cost for such type of space vehicle would be about USD 600,000 per launch (Mirchandani, Rajesh., 2008) and each launch would have six suborbital tourists (Accelteon Partners Inc., 2008). Therefore the estimated head cost per passenger per flight would be USD 0.12 million. However it has been assumed that due to future technological advancements, this head cost would be reduced to USD 0.09 million per passenger. Presently, the marketing costs being incurred by Virgin Galactic is assumed to be US $\$ 1,800,000$ per year. It has been assumed that by 2013, this marketing cost would also decline by $25 \%$ to USD 1.35 million. Based on the foregoing estimates, the expected cash flow for a company has been computed which would launch 104 spaceflights to meet the demands of 624 tourists per annum between 2010 and 2020.

\begin{tabular}{|l|l|l|}
\hline Nature & Cost Items & Amount in million US \$ \\
\hline Fixed Cost & $\begin{array}{l}\text { Design, Development, Testing, Evaluation } \\
\text { \& Production(5 SS2+2 WK2) }\end{array}$ & 350 \\
\cline { 2 - 3 } & Spaceport Lease charge(20 yrs) & 27.5 \\
\cline { 2 - 3 } & Regulatory Cost(20Yrs) & 4.769352 \\
\hline \multirow{2}{*}{ Variable Cost } & Operating Cost/pax & 0.09 \\
\cline { 2 - 3 } & Marketing Cost/year & 1.35 \\
\hline
\end{tabular}

Table 2: Cost Structure of a Company Operating Suborbital Trips

For this computation, it has been assumed that the company would disburse an amount of USD $132,269,352$ in the year 2010; as payment for research and development, spaceport lease and regulatory charges. Then again incur USD 250 till 2012. In 2013 when the price of such travel has declined to USD 150,000 it is expected that the demand for suborbital travel in India will increase. If this company is able to meet the hypothetical demand of 624 Indian suborbital passengers per year then the expected cash flow would be USD 93.6 million.

By the year 2020, it is expected that the company would lower its operating and marketing costs by a further $25 \%$ to US $\$ 0.06$ million /launch and US $\$ 0.09$ million/year by 2030 .This cost reduction due primarily to technological advancements would in turn lead to price reductions. If competition in this sector increases, it is assumed that the company will lower the ticket price to USD 100,000 per passenger.

\begin{tabular}{|l|l|l|}
\hline \multicolumn{2}{|l|}{ Expected Cash Flows } & \\
\hline Year & Expected Revenue (Inflow) & Expected Cost (outflow) \\
\hline 2010 & & -132.269352 \\
\hline 2011 & & -100 \\
\hline 2012 & & -150 \\
\hline 2013 & 93.6 & -57.51 \\
\hline 2014 & 93.6 & -57.51 \\
\hline 2015 & 93.6 & -57.51 \\
\hline 2016 & 93.6 & -57.51 \\
\hline 2017 & 93.6 & -57.51 \\
\hline 2018 & 93.6 & -57.51 \\
\hline 2019 & 93.6 & -57.51 \\
\hline 2020 & 93.6 & -57.51 \\
\hline 2021 & 62.4 & -38.34 \\
\hline 2022 & 62.4 & -38.34 \\
\hline 2023 & 62.4 & -38.34 \\
\hline 2024 & 62.4 & -38.34 \\
\hline 2025 & 62.4 & -38.34 \\
\hline 2026 & 62.4 & -38.34 \\
\hline 2027 & 62.4 & -38.34 \\
\hline 2028 & 62.4 & -38.34 \\
\hline 2029 & 62.4 & -38.34 \\
\hline 2030 & 62.4 & -38.34 \\
\hline
\end{tabular}

Table 3: Expected Cash Flows for Suborbital Trip

On this expected cash flow it has been found that Net Present Value would be USD -168.28 million for operations up until 2030 assuming the rate of interest to be constant at $10 \%$. Therefore we can conclude at this stage that it might not be advisable to invest in this venture as the company would incur a loss of USD -168.28 
million. IRR for this expected cash flow comes out at $2 \%$. Therefore it can be said that, at present, it is not profitable to operate suborbital flights for tourism given the cost structure.

\section{f. Estimating the Cost of Orbital Flights and Financial Planning}

Our cost structure is based on the inferences of an economic model known as the "Cost and business analysis module" (CABAM) and "Launch marketing for normal ordinary people" (LMNOP) developed at Space System Design Laboratories at the School of Aerospace Engineering of the Georgia Institute of Technology and published in September 2006 by the American Institute of Aeronautics and Astronautics (Depasquale, Dominic et. al., 2006).

According to this Study, a hypothetical company operating under certain assumptions would have the cost structure shown in Table 4 below:

\begin{tabular}{|l|l|l|l|}
\hline & Optimistic & Most Likely & Pessimistic \\
\hline $\begin{array}{l}\text { DDTE (Design development testing and } \\
\text { evaluation) }\end{array}$ & 100 & 225 & 300 \\
\hline TFU(Theoretical first unit cost) & 52 & 66.5 & 84 \\
\hline Fixed Operating Cost/year & 5 & 5.75 & 6.8 \\
\hline Variable Operating cost/flight & 5.5 & 49.6 & 76 \\
\hline Facilities Development cost & 30 & 50 & 100 \\
\hline Number of Flights & 5 & 12.5 & 30 \\
\hline
\end{tabular}

Table 4: Cost Structure of Company Operating Orbital Flights

The following assumptions are made for purposes of financial planning based on the cost structure of the company:

a. The company is vertically integrated and is developing the vehicle, acquiring the fleet and operating the ground and operating activities to provide the experience of orbital travel to the consumer.

b. This model has analyzed only the cost of the transport operator. Any space destination/hotel operator in space is not factored in the analysis.

c. The initial operating capability of the project is assumed to be 2013 with DDTE starting from 2010; fleet acquisition and ground handling occurring from 2011-12 and 13 years of flight operations (i.e., till 2025).

From the foregoing, three scenarios of expected cash flows for the company: Optimistic; Most likely; and, Pessimistic. Taking the analysis further, the sensitivities in our financial estimates has been incorporated in order to arrive at the Net Present Value (NPV) and Internal Rate of Return (IRR) for the three scenarios. See Table 5 below:

\section{Sensitivity Analysis}

\begin{tabular}{|l|l|l|l|}
\hline & Optimistic & Most likely & Pessimistic \\
\hline NPV@ 10\% & $\begin{array}{l}\text { USD 472.93 } \\
\text { million }\end{array}$ & $\begin{array}{l}\text { USD (\$519.46) } \\
\text { million }\end{array}$ & $\begin{array}{l}\text { USD } \\
\text { million }\end{array}$ \\
\hline IRR & $45 \%$ & Negative & Negative \\
\hline
\end{tabular}

Table 5: Sensitivity Analysis of Cost Structure of Company Offering Orbital Trips

For the optimistic situation the NPV and IRR are USD 472 million and $45 \%$ respectively. A Positive NPV signifies that investment in the venture is quite good. NPV at 10\% shows a profitable venture and IRR at $45 \%$ shows that market fluctuations cannot have much effect on the profit margin of the company engaged in this business.

In the "most likely" scenario, the estimates show a negative NPV (i.e. USD - \$519 million and IRR is also negative. This is because variable costs would have increased by $150 \%$ thus making the venture a lossmaking one. It is advisable not to set up a business in this venture unless there is a dramatic reduction in the cost.

With respect to the "pessimistic" scenario, the estimates show a negative NPV (i.e., USD - $\$ 3,560$ million) and IRR is also negative. Negative NPV suggests that it would not be profitable to do business under this scenario whereas the negative IRR suggests that it is not at all viable to finance this project. As the variable cost in our model is assumed to increase by about 600\% from USD 200 million (optimistic) to USD 1200 million (pessimistic), this in turn changes NPV values from positive to negative. Thus, feasibility analysis of this business is much dependent on what will be the variable cost of providing this service.

To conclude, it can be safely said that orbital space tourism will be a really good venture to invest in if the variable costs of providing this service falls within the range of optimistic estimates as shown in Table 4 
above. However, if the variable cost falls within the "most likely" or "pessimistic" scenarios, then the viability of providing orbital flight service would become questionable.

\subsection{Entrepreneurial Interest}

So far, the financial analysis demonstrates that NPV for suborbital travel at $10 \%$ rate of interest is negative and IRR is merely $2 \%$ which shows that no prudent entrepreneur would like to venture into such a project. However, various secondary sources of revenue such as theme and virtual reality space parks; space camps; training, production and launch recovery facilities parks; trip training facilities etc have not been considered.

While in the case of orbital travel it has been found that under the optimistic scenario, cost estimates show a very promising return, a slight variation in the type of vehicle used could result in high fuel costs which will immensely affect the feasibility of the project. Thus, the viability of space tourism is primarily dependent on the type of vehicle which will be available to transport passengers.

Therefore to boost entrepreneurial interest in this sector, it is imperative for government to waive or reduce the tax burden in the initial years and to provide subsidies for research and development in the space tourism sector.

Although there are significant roadblocks which are hindering the growth of space tourism in India, it is believed that in the coming decade, space tourism demand will definitely become established and grow in India. The growth will most likely be attributed to the grovelling Indian economy. The Indian economy is going to add millionaires at the fastest rate in the world. This statement provides great optimism for the commencement of the space tourism industry at least from demand side. All that is required is to address the supply-side challenges.

\section{Conclusion}

It has been seen that there is presence of demand for space tourism in India. At present the supply remains the major constraint in both sub-orbital and orbital trip. The constraint of supply will be removed in due course of time with the technological advancement. What is need of hour in connection to space tourism in India is to enact appropriate national space laws and regulations which encourages and assists this new industry.

Particularly, in order to attract private investments into the sector, the government should provide tax benefits and subsidies for research and development at least during the initial stages. The growth of space tourism would enable to generate employment and also enhance India's global credibility as a high-tech, fast developing nation in the long run.

\section{References}

[1]. Accelteon Partners Inc. (2008). Space tourism: how it will change the world. Richmond Hill. Canada.

[2]. Ashworth Stephen (2012, February 1). The key to low cost access to space commerce. Astronautical Evolution, Issue 78. Washington D.C.

[3]. Chow, Dennis. (2011, April 25). Future of space tourism: who is offering what. Retrieved from www.space.com.

[4]. Coppinger, Rob. (2009, April 14). Space tourism: Galactic Gamble - Is the market Virgin's to lose? Flight International. London.

[5]. Depasquale, Dominic, Charania, A.C. and Olds, John R. (2006, September 19-21). The emerging orbital space tourism industry: new insight into demand and prospects for success. American Institute of Aeronautics and Astronautics Inc. San Jose, California.

[6]. Forget the plane, take intercity spaceship. (2008, February 02). Retrieved from www.newscientist.com.

[7]. Futron Corporations. (2006). Sub-orbital space tourism demand revisited. Bethesda USA.

[8]. Helm, Burt. (2004, October 15). Virgin galactic space odyssey. Business Week. Retrieved from www.businessweek.com.

[9]. Mirchandani, Rajesh. (2008, July 28) Branson unveils space tourism jet. BBC News. Retrieved from www.bbcnews.co.uk.

[10]. Olds, J. McCormic, D. Charania, \& Marcus, L. (2000, October 02-06). Space tourism: making it work for fun and profit. 51 International Astronautical Congress. Rio de Janerio, Brazil.

[11]. Pelton, J.N. (2007). Space Planes and Space Tourism: The Industry and the Regulation of its Safety. George Washington University. Washington D.C. USA.

[12]. Space Future Consulting. (2008). Space tourism: the story so far. Retrieved from www.spacefututre.com.

[13]. University of Petroleum \& Energy Studies. (2011, March 31). Space tourism in India: an interdisciplinary research project. Dehradun, India. 